\title{
O processo de elaboração de cartilhas para orientação do autocuidado no programa educativo em Diabetes
}

\author{
The process of creating guidebooks for orienting self-care in the Diabetes educational program
}

El proceso de elaboración de cartillas para orientar el autocuidado en el programa de educación en Diabetes

\author{
Heloisa Carvalho Torres', Naiara Abrantes Candido', \\ Luciana Rodrigues Alexandre', Flávia Lobato Pereiral \\ 'Universidade Federal de Minas Gerais. Departamento de Enfermagem. Belo Horizonte, MG
}

Submissão: 08/01/2009

Aprovação: 23/02/2009

\section{RESUMO}

Este estudo teve como objetivo descrever a experiência da elaboração de cartilhas sobre a educação do autocuidado realizada junto aos indivíduos com Diabetes do Hospital-Escola, por docentes e alunos de graduação da Escola de Enfermagem da Universidade Federal de Minas Gerais. A partir das oficinas de saúde realizada com docentes e alunos, foram levantados problemas e Questões relacionadas ao autocuidado em Diabetes. Com base na filosofia freireana, foram realizados encontros com os indivíduos com Diabetes, seguindo um roteiro de trabalho para a construção das cartilhas Que incluiu a seleção de conteúdos, estilo e formato do material. A criatividade presente nas imagens durante as discussões sobre os assuntos fez dos encontros um rico momento de troca, em Que os participantes expuseram idéias, valores, crenças, e histórias de vida. As mensagens foram bem planejadas, compreensíveis e atrativas, e os indivíduos consideraram-nas eficazes para auxiliar nas atividades educativas e no autocuidado em Diabetes.

Descritores: Manuais; Autocuidado; Diabetes; Educação em Saúde.

\begin{abstract}
This study aimed at describing the experience of creating guidebooks on self-care, performed with individuals with diabetes of the Teaching Hospital, by professors and undergraduate students of the Nursing School at Universidade Federal de Minas Gerais. Problems and issues related to self-care and diabetes were raised in the healthcare workshops held with professors and students. Based on Freire's methodology, meetings were held with individuals with diabetes according to directives for the construction of the guidebooks that included the selection of content, style and format of the material. The creativity present in the images during the topic discussions made the meetings into a rich moment of exchange, where the participants could express ideas, values, beliefs and life histories. The messages were well-planned, comprehensible and attractive, and the individuals considered them effective in helping them in the educational activities and diabetes self-care.
\end{abstract}

Descriptors: Handbooks; Self-Care; Diabetes; Health Education.

\section{RESUMEN}

Este estudio objectivó describir la experiencia de elaborar cartillas para educar sobre el autocuidado. Ejecutado por docentes y alumnos de graduación de la Escuela de Enfermería de la Universidad Federal de "Minas Gerais" con personas Diabéticas del Hospital/Escuela. Realizando talleres en salud, ejecutado por docentes y alumnos, siendo levantados problemas y preguntas relacionadas al autocuidado en Diabetes. Fundamentados en Freire fueron realizadas reuniones con personas diabéticas utilizando una guía de trabajo para la construcción de cartillas, que incluyó la selección de contenidos, estilo y formado del material. La creatividad en las imágenes generó discusiones de intercambio enriquecedoras sobre el asunto, en las cuales los participantes expusieron ideas, valores, creencias e historia de vida. Los mensajes fueron muy bien planificados, comprensibles y atractivos, siendo considerados por los sujetos eficaces y de apoyo en las actividades educativas y en el autocuidado sobre Diabetes.

Descriptores: Manuales: Autocuidado, Diabetes, Educación en Salud. 


\section{INTRODUÇÃO}

O presente trabalho apresenta a experiência da disciplina Interdisciplinaridade na Educação em Diabetes, em parceria, com o programa de diabetes desenvolvido no Serviço Especial de Endocrinologia e Metabologia do Ambulatório Borges da Costa do HC/UFMG, buscando envolver seus docentes e estudantes no processo de ensino-aprendizagem para a educação do autocuidado. Em uma perspectiva de articulação entre ensino e pesQuisa, a eQuipe multidisciplinar do programa educativo em diabetes propõe aos alunos do curso de graduação em Enfermagem e Nutrição a participação no processo de elaboração do material informativo/ educativo para a orientação do autocuidado da doença.

O processo de elaboração das cartilhas educativas sobre o autocuidado em Diabetes teve por base os princípios da prática educativo-dialógica aplicada à pedagogia da saúde com base na filosofia freireana. Tal processo traz subsídios à possibilidade de auxiliar o paciente a modificar o seu estilo de vida e ser o agente de transformação ${ }^{(1,2)}$. O paciente tem a oportunidade de ampliar a sua compreensão sobre o problema e refletir a respeito da intervenção sobre a realidade Que o contextualiza, privilegiando o desenvolvimento da sua autonomia ${ }^{(3)}$.

O uso crescente de materiais educativos como recursos na educação em saúde tem assumido um papel importante no processo de ensino-aprendizagem ${ }^{(4,5)}$, principalmente na intervenção terapêutica das doenças crônicas. É especialmente útil no diabetes, pois melhora o conhecimento e a satisfação do paciente, desenvolve suas atitudes e habilidades, facilita-lhes a autonomia, promove sua adesão e os torna capazes de entender como suas próprias ações influenciam seu padrão de saúde ${ }^{(6)}$.

Embora haja algumas limitações decorrentes de dificuldades de leitura pelo receptor, as cartilhas educativas permitem ao paciente e sua família uma leitura posterior, reforçando as informações orais, servindo como guia de orientações para casos de dúvidas e auxiliando nas tomadas de decisões do cotidiano. Esses objetivos podem ser alcançados ao se elaborar mensagens Que tenham vocabulário coerente com o público-alvo, convidativas, de fácil leitura e entendimento ${ }^{(7)}$.

Assim, pretende-se neste trabalho descrever a experiência da elaboração de cartilhas sobre a educação do autocuidado, realizada junto aos indivíduos com diabetes no Hospital-Escola por docentes e alunos de graduação da Escola de Enfermagem da Universidade Federal de Minas Gerais.

\section{MÉTODO}

Os passos do processo de elaboração das cartilhas educativas foram: 1) Caracterização preliminar dos sujeitos do estudo; 2) O processo de construção das cartilhas educativas; 3) Grupo operativo e entrega do material didático-instrucional.

$I^{\circ}$ passo: Caracterização preliminar dos sujeitos do estudo no atendimento individual

Participaram do estudo 25 indivíduos com diabetes tipo 2 em seguimento no Programa Educativo em Diabetes do Hospital/Escola de Belo Horizonte /MG. Identificou-se o perfil dos sujeitos envolvidos a partir de consultas individuais da Enfermagem e da Nutrição. Nestas, foi possível conhecer as características sócio- demográficas dos indivíduos, o diagnóstico clínico, estilo de vida em relação a prática de atividades físicas e ao plano alimentar, o tratamento e o controle glicêmico, dificuldades pessoais, além de verificar o interesse e a disponibilidade para participar do processo de elaboração do material informativo/educativo.

$2^{\circ}$ Passo: $O$ processo de construção das cartilhas educativas

O trabalho foi iniciado com um estudo-piloto realizado na disciplina Interdisciplinaridade na Educação em Diabetes, de caráter optativo, com carga horária de 60 horas, para alunos a partir do $4^{\circ}$ período do curso de graduação em Enfermagem e em Nutrição da Escola de Enfermagem da Universidade Federal de Minas GeraisEE/UFMG, em Belo Horizonte em 2008. O corpo docente da disciplina foi composto por um enfermeiro docente da EE/UFMG e cinco outros profissionais de saúde (médico, enfermeiro, fisioterapeuta, nutricionista e terapeuta ocupacional) do Serviço de Endocrinologia e Metabologia do Ambulatório Borges da Costa do HC/UFMG, envolvidos no Programa Educativo em Diabetes.

Foram planejadas três oficinas de saúde sobre a elaboração de cartilhas com os alunos e docentes. Os alunos foram orientados a produzir um material didático instrucional dirigido à educação do autocuidado em Diabetes. Logo em seguida, elaboraram a proposta e organizaram os encontros com os indivíduos com diabetes para apresentar e discutir a projeto. Solicitaram aos participantes Que expressassem suas dúvidas Quanto aos conhecimentos sobre a doença, atividade física e plano alimentar e seus problemas e necessidades em relação à doença.

O projeto foi aprovado pelo Comitê de Ética em Pesquisa (Parecer $n^{\circ}$. ETIC 153/07).

O instrumento utilizado para a coleta de dados consistiu em um Questionário semi-estruturado, focado nos seguintes Questionamentos:

- Fisiopatologia: Definição da doença, sintomas, complicações crônicas, como proceder em casos de hiper e hipoglicemia, dificuldades em controlar a glicemia, medicamentos.

- Atividade Física (AF): importância do exercício para a doença; importância da avaliação médica antes de iniciar uma AF; hipoglicemia e AF; freqüência mínima, melhor horário e duração da AF; pirâmide da AF; insulina e AF; contra-indicações.

- Alimentação: orientação sobre alimentos "proibidos e permitidos"; dificuldade em seguir as orientações sobre alimentação saudável; importância das fibras; mitos da alimentação; diet e light; adoçantes; periodicidade das refeições.

As informações coletadas foram devidamente organizadas e sistematizadas, estabelecendo os problemas prioritários dos indivíduos. A partir dos resultados encontrados na entrevista, os alunos e os docentes elaboraram as cartilhas, tendo por base a literatura técnico-científica e experiência profissional. O material confeccionado foi apresentado na disciplina para uma avaliação preliminar pelos alunos e docentes, e posteriormente aos sujeitos do estudo.

$3^{\circ}$ Passo: Grupos operativos e entrega do material educativo

Foram organizados os grupos operativos, com os sujeitos participantes do estudo, para a entrega das cartilhas com o intuito de discutir e fornecer sugestões para melhorar o material e facilitar a sua compreensão. Nos três encontros semanais eram abordados temas sobre: fisiopatologia, nutrição e atividade física. Os encontros eram coordenados por uma equipe composta por enfermeiro, 
terapeuta ocupacional, fisioterapeuta, acadêmicos de enfermagem e nutrição. Dessa equipe, um era o mediador, responsável pelo desenvolvimento do conteúdo temático; e um era o observador, responsável por anotar as falas e enfatizar as idéias nelas contidas.

A avaliação do material foi realizada por meio de um Questionário semi-estruturado sobre os aspectos relacionados à organização, estilo de escrita, aparência e motivação das cartilhas.

Assim, nossos objetivos para cada passo foram: Passo I: Definição dos participantes; Passo II: Apresentação dos temas a serem trabalhados, a elaboração da mensagem e definição de estratégias para apresentar os conteúdos no material; Passo III: Avaliação dos conteúdos e confecção.

\section{RESULTADOS E DISCUSSÃO}

Caracterização dos Indivíduos para a Construção das Cartilhas

Observou-se no estudo uma população adulta com idade média de 55 anos, com maior freeüência de mulheres 94\% (25); baixa escolaridade; glicose sanguínea elevada - HbAl c: 10\%; tempo de duração do DM: 10 anos; alto Índice de Massa Corporal - IMC: $29,98 \mathrm{Kg} / \mathrm{m}^{2}$. Esse perfil dos indivíduos é semelhante ao encontrado em alguns estudos, sugerindo a necessidade de se conhecer a população-alvo para elaborar os materiais educativos de acordo com as suas necessidades ${ }^{(9,10)}$. Apesar do baixo nível de escolaridade limitar o acesso às informações, devido ao possível comprometimento das habilidades de leitura, escrita, compreensão ou mesmo da fala ${ }^{(11,12)}$, verificou-se que os indivíduos possuíam conhecimento relacionado à patogenia do diabetes. Tal fato pode estar relacionado com esse público específico, Que recebe suporte educativo contínuo da equipe multidisciplinar do ambulatório de especialidades do HC/UFMG. Esse apoio educacional tem um impacto positivo sobre o comportamento das pessoas com DM, sua evolução de saúde.

\section{A construção da Proposta das Cartilhas Educativas}

Diante da proposta de desenvolvimento das cartilhas destinadas aos indivíduos com diabetes tipo 2, o público-alvo mostrou-se interessado. Decidiram pela confecção de uma cartilha educativa ilustrada com figuras, para tirar dúvidas, Que pudesse ser levada para o domicílio, e Que seria mais acessível para o autocuidado, facilitando a comunicação visual e o acesso por parte dos sujeitos com pouca familiaridade com a linguagem escrita. Esse procedimento foi fundamentado na filosofia freireana, permitindo Que a educação ocorra em uma relação horizontal, dialógica, recíproca e verdadeiramente humana, estimulando de forma eficaz o autocuidado ${ }^{(1)}$.

A escolha por construir um material de forma conjunta entre pacientes, alunos e docentes favorece uma ação educativa, em Que se busca a troca de experiências e informações, reflexão e problematização sobre os temas, assumindo suas experiências cotidianas de vida como fonte de conhecimento e de ação transformadora da realidade ${ }^{(15)}$.

\section{- A escolha do formato para o impresso}

As cartilhas - fisiopatologia, atividade física e alimentação - foram confeccionadas em folha A4 $(210 \times 297 \mathrm{~mm})$ em formato de configuração "paisagem". O tamanho da página foi de meia folha. Os participantes optaram pelo texto no formato pergunta/resposta, sendo sempre acompanhado por uma ilustração. Esse formato aumenta a retenção do conteúdo pelo leitor ${ }^{(7)}$.

Os textos foram escritos utilizando-se a fonte Comic Sans MS de tamanho 14 pontos na cor vermelha para as perguntas, e a fonte Arial de tamanho 14 pontos na cor preta para as respostas. Preocupou-se na elaboração de mensagens breves, considerando Que frases longas reduzem a velocidade do processo de leitura e geralmente os leitores esquecem os itens de listas muito grandes ${ }^{(4,8)}$. Além disso, foi utilizada linguagem simples, objetivando promover a identificação do paciente com o texto e manter a sua iniciativa no processo da educação em saúde.

$\mathrm{Na}$ cartilha produzida, utilizou-se desenhos de linhas simples, de forma a complementar e reforçar as informações escritas. Alguns autores $^{(4,5)}$ destacam a importância da ilustração para atrair o leitor, despertar o interesse pela leitura e auxiliar na compreensão do texto. Os materiais educativos foram apresentados e discutidos nos três encontros dos grupos operativos com os sujeitos do estudo.

Organização e Detalhamento dos Temas nos Grupos Operativos

A primeira cartilha abordou o tema: Aprendendo a lidar com o diabetes mellitus tipo II - foi abordado no primeiro encontro por meio de uma peça teatral, apresentando o conteúdo e os personagens presentes no material educativo. Inicialmente o "Sr. Glicose" explicou Que ele se encontra nos alimentos, no sangue e na célula. Logo em seguida, a "Chave", personagem designado para representar a insulina, fala da sua função em "abrir a porta da célula" para que o "Sr. Glicose" consiga entrar. Utilizando esses personagens, foi possível explicar a fisiopatologia do diabetes, mostrar os sintomas da doença, a importância do uso correto do medicamento, insulinoterapia, complicações do diabetes e os sintomas da hiper e hipoglicemia.

A segunda cartilha foi sobre atividade física e diabetes tipo 2: dúvidas freeüentes sobre o tema - abordou a importância da AF; a necessidade de uma avaliação médica antes da AF; freqüência, duração e horário do exercício; hipoglicemia e insulinoterapia na AF. Em cada pergunta havia uma figura Que facilitava a compreensão da mensagem. No encontro, os indivíduos fizeram as perguntas presentes no material educativo e, após a discussão do tema, foram lidas as respostas encontradas na cartilha e discutidas as dúvidas.

A terceira foi sobre Diabetes: o Que comer? - continha na capa a pirâmide alimentar com o número de porções recomendadas para todos os grupos de alimentos. Logo em seguida havia informação sobre número de refeições Que deve ser realizado ao longo do dia com uma sugestão de cardápio. O processo da digestão, a diferença entre diet e light, rótulo dos alimentos e adoçantes também foram abordados, utilizando os personagens da primeira cartilha: o Sr. Glicose e a Chave. O material foi apresentado por meio de uma roda de conversa, com exemplos cotidianos e explicações simples Que estimularam a participação dos pacientes.

Foi possível perceber um grande interesse dos indivíduos pela alimentação, expresso por meio de dúvidas e comentários a respeito da dificuldade de conseguir uma consulta individual de Nutrição e da escassez de grupos operativos nas Unidades Básicas de Saúde (UBS). Tal fato pode ser confirmado em um estudo ${ }^{(16)}$ no Qual foi verificado um número pequeno de UBS Que possui um Serviço de Nutrição e Que participam no processo de educação em saúde.

Todos os participantes relataram já ter recebido orientações sobre 
a alimentação e atividade física. Porém, 80\% (25) destes relataram ter dificuldade em seguir estas orientações. Um estudo mostra Que pessoas com Diabetes Que receberam informações ao longo do período da doença podem ter limitado/impedido sua incorporação por fatores intervenientes no processo de aQuisição dessas informações ${ }^{(9)}$. É fundamental Que a educação em saúde considere a realidade dos pacientes, seu conhecimento prévio e suas dúvidas, a fim de transformar o sujeito passivo no seu tratamento em um indivíduo participativo ${ }^{(13)}$. O papel do paciente como sujeito ativo, Que entende e concorda com a conduta tomada pela equipe de saúde, assumindo responsabilidades sobre seu tratamento, é um fator decisivo para o sucesso da terapêutica.

No decorrer dos encontros, observamos uma troca de experiências, com a participação dos pacientes citando seus próprios exemplos em relação ao Quadro clínico e a terapêutica. Os relatos foram valorizados pelos profissionais da saúde, docentes e alunos para a elaboração das cartilhas.

\section{- Avaliação do material didático-instrucional}

Durante a aplicação dos Questionários, os participantes alegaram conhecer a maioria das informações Questionadas. Além disso, 75\% (25) dos indivíduos demonstraram interesse em aprender mais sobre os assuntos. Tal fato evidencia Que o diabetes necessita de uma educação continuada, como mencionado em alguns estudos ${ }^{(9-12)}$, a fim de auxiliar o paciente na adaptação às mudanças e, conseQüentemente, prevenir as complicações agudas e crônicas da doença.

Especificaram, a partir dos Questionamentos, dúvidas Quanto ao nível ideal da glicemia; formas para auxiliar no controle da doença; adoçantes; alimentos permitidos; diet/light; freQüência e tempo de duração recomendados para atividade física. A compreensão desses assuntos proporciona ações Que modificam o comportamento no cotidiano. Nesse sentido, destaca-se a necessidade do material impresso para assegurar uma assistência Que atenda às necessidades do individuo facilitando a autonomia e promovendo a adesão ao tratamento ${ }^{(5)}$.

Os indivíduos foram Questionados Quanto ao conteúdo das cartilhas, linguagem, layout e ilustrações. Esses aspectos podem ser facilitadores/dificultadores no processo de leitura do material ${ }^{(5,8)}$. Alguns sujeitos apresentaram dificuldade em entender uma das figuras presentes na cartilha de nutrição, na Qual há associação da insulina com uma chave e da célula com uma porta. O restante das figuras foi considerado atraente e facilitador para a compreensão do texto.

A apresentação da diagramação foi considerada adecuada, com ilustrações dispostas de maneira Que o leitor conseguisse entendêlas, legendas com mensagens-chave, letras que facilitaram e motivaram a leitura, cores atraentes, mas sem deixar o material visualmente poluído. O processo de elaboração das cartilhas com a participação do receptor também se mostrou eficaz Quanto à adequação do conteúdo Que atendeu a necessidade dos pacientes.

Apesar da escassez de trabalhos nacionais avaliando os materiais impressos veiculados, alguns estudos confirmam Que a participação do receptor na elaboração do material educativo é extremamente importante para se alcançar o objetivo proposto ${ }^{(4,8)}$.

A adequação da linguagem científica para uma linguagem acessível ao público-alvo e a seleção de figuras didáticas e chamativas foram apontados como dificuldades pelos alunos na elaboração da cartilha. Porém, este processo é necessário, visto que tais elementos podem ser dificultadores/facilitadores da compreensão da mensagem veiculada $^{(4,8)}$

Os alunos sentiram dificuldades na elaboração das cartilhas em relação à separação dos temas, porém ressaltaram que essa atividade mostrou a importância do profissional em buscar a troca de conhecimentos de sua área temática, considerando a interdependência entre as especialidades, levando cada um a reforçar as exposições feitas pelos colegas ${ }^{(14)}$.

O desenvolvimento de uma cartilha educativa, na Qual os indivíduos atuam efetivamente no processo de desenvolvimento do material, mostrou-se eficaz na condução do alcance do objetivo proposto, estimulando novas estratégias educativas.

\section{CONSIDERAÇÕES FINAIS}

A experinecia demonstrou Que o material escrito tem uma contribuição valiosa para se desenvolver habilidades e favorecer a autonomia do indivíduo. É importante criar, desenvolver e produzir um material de Qualidade Que alcance as necessidades do indivíduo com diabetes.

Consideramos, também, Que este estudo pôde contribuir com a formação de profissionais de saúde melhor preparados para atuar no contexto em Que este está inserido com vistas à assistência integral e ao trabalho interdisciplinar, partindo do pressuposto de Que a participação do indivíduo possibilita a aQuisição de conhecimentos e a troca de experiências.

Esse estudo possibilitou o desdobramento para futuras pesquisas a respeito da elaboração e desenvolvimento do manual educativo sobre diabetes direcionadas para os profissionais de saúde.

\section{REFERÊNCIAS}

I. Freire P. Pedagogia do oprimido. Rio de laneiro: Paz e Terra; 1988.

2. Zanetti ML, Biagg MV, Santos MA, Péres DS, Teixeira CRS. O cuidado à pessoa diabética e as repercussões na família. Rev Bras Enferm 2008; 61(2): 186-92.

3. Torres HC, Salomon IMM, Jansen AK, Albernaz PM. Interdisciplinaridade na educação em Diabetes: percepção dos graduandos de enfermagem e nutrição. Rev Enferm UERJ 2008; I6(3): 35 I-7.

4. Oliveira VLB, Landim FLP, Collares PM, Mesquita RB, Santos ZMSA. Modelo explicativo popular e profissional das mensagens

de cartazes utilizados nas campanhas de saúde. Texto Contexto Enferm 2007; 16(2): 287-93.

5. Moreira MF, Nóbrega MML, Silva MIT. Comunicação escrita: contribuição para a elaboração de material educativo em saúde. Rev Bras Enferm 2003; 56(2): 184-8.

6. Selli L, Papaleo LK, Meneghel SN, Torneros IZ. Técnicas educacionales em el tratamiento de La diabetes. Cad Saúde Pública 2005; 21 (5): 1366-72.

7. Freitas AAS, Cabral IE. O cuidado à pessoa trąueostomizada: análise de um folheto educativo. Esc Anna Nery Rev Enferm 2008; 12(1): 84-9. 
Torres HC, et al.

8. Thiolent M. Metodologia da Pesquisa-Ação. São Paulo: Cortez Editora; 1986

9. Alvim NAT, Ferreira MA. Perspectiva problematizadora da educação popular em saúde e a enfremagem. Texto Contexto Enferm 2007; 16(2): 315-9.

10. Alves VS, Nunes MO. Health education in connection with medical attention to hypertensive patients in the family health program. Interface - Comunic Saúde Educ 2006; 10(19): 131-47.

1 1. Fonseca LMM. Cartilha educativa para orientação materna sobre cuidados com o bebê prematuro. Rev Latino-am Enfermagem 2004; 12(1): 65-75.
12. Kelly-Santos A, Rozemberg B. Comunicação por impressos na saúde do trabalhador: a perspectiva das instâncias públicas. Ciênc Saúde Coletiva 2005; 10( 4):89-95.

13. Fernandes JD, Ferreira SL, La Torre MPS, Santa Rosa DO, Costa HOG. Estratégias para a implantação de uma nova proposta pedagógica na escola de enfermagem da Universidade Federal da Bahia. Rev Bras Enferm 2003; 56(4): 392-5.

14. Cintra SMP, Silva CVR, Circéia A. O ensino do brinquedo/ brinquedo terapêutico nos cursos de graduação em enfermagem no Estado de São Paulo. Rev Bras Enferm 2006; $59(4$ ): 497 501 . 